\title{
Early Malaria diagnosis and treatment seeking Behavior among clients attending outpatient department Sekou-Toure regional referral Hospital in Mwanza, Tanzania; A Cross-Sectional Study
}

Samson Peter Mvandal ( $\sim$ samsonpim@gmail.com )

Catholic University of Health and allied sciences https://orcid.org/0000-0002-4996-6266

Gotfrida Marandu

Catholic university of Health and Allied sciences

\section{Research Article}

Keywords: Early diagnosis, behavior, illness, malaria, Mwanza, treatment-seeking, Tanzania

Posted Date: January 10th, 2022

DOI: https://doi.org/10.21203/rs.3.rs-1241937/v1

License: (c) (i) This work is licensed under a Creative Commons Attribution 4.0 International License.

Read Full License 


\section{Abstract \\ Background}

Early diagnosis of malaria and treatment seeking behavior play key role in controlling and preventing further complication related to malaria disease. Aim of this study was to determine the responses on early malaria diagnosis and treatment seeking behavior among outpatient clients attending at Sekou toure regional referral hospital in Mwanza, Tanzania.

\section{Methods}

A cross-sectional study was conducted among outpatient client at Sekou-Touré regional referral hospital, convenient simple random sampling used and self-administered questionnaire were used to collect data and data was entered into Microsoft excel and then exported to SPSS version 25.0 for further analysis and presented on the percentages and table. The analysis of strength of relationships between categorical variables was conducted using the Chi-square test. A p-value of $\leq 0.05$ was considered to be statistically significant.

\section{Results}

A total of 192 respondents completed the study with a response rate of $97.6 \%$. The study revealed that Most of the respondents about $90.6 \%$ stated they would seek treatment from health facility when symptoms appear. However, only $6.3 \%$ seek treatment within 24 hours of onset of illness $(p=0.017)$. Half of respondents (50.5\%) experienced malaria symptoms in the past six months and only $30 \%$ seek for treatment at health facility. Preference of health facility, (51\%) respondents were going direct to pharmacy to buy medicine for self-treatment. Overall, cost of service, time consumed and distance of health facility especially health center shows significant with such delay.

\section{Conclusion}

A low proportion of malaria-suspected patients sought treatment within $24 \mathrm{~h}$ of fever onset compared to the national target. Distance from the health facility, cost of service and time consumed were found to be predictors of early treatment-seeking behavior for malaria. Strengthening strategies tailored to increasing awareness for communities about malaria, importance of going hospital and early treatment-seeking behavior is essential.

\section{Paper Context}

The findings of this study could help Malaria Elimination Program to plan for community Information Education and Communication Program (IEC) on the importance of seeking early diagnosis, proper 
treatment and ensure availability of ACTs and microscope or MRDTs in all health facilities. Lastly, it is important to community specific behavioral intervention so as to improve knowledge of the community on true malaria picture in country

\section{Introduction}

Malaria in Tanzania is still a challenge that affect general welfare of people and is a leading cause of morbidity and mortality and most affected are the pregnant women and the children under 5 years $^{[1]}$. There are control tools recommended for early detection is quality-assured diagnostic like MRDT and treatment of malaria cases with artemisinin-based combination therapy (ACT), which helps in assurance early detection and also in medical management of malaria. ${ }^{[2]}$

World Health Organization in Geneva 2013, show that early treatment seeking is helpful in ruling out the disease and help in preventing and controlling malaria through prompt recognition of symptoms and signs of malaria from household level to community level ${ }^{[3]}$ Early treatment also requires that appropriate health services and medication are accessible and used. [3]

Treatment seeking behavior for malaria need to be undertaken to identify patterns of care seeking and to assess what is known about the adequacy of the treatments used. ${ }^{[4]}$ Study done in Ethiopia it shows that early diagnosis and treatment of malaria should take place within 24 hours of the onset of symptoms. ${ }^{[4]}$

Healthcare seeking behavior vary among those who utilize health facilities like hospitals, dispensaries and those who self-purchase of drugs exclusively on self-treatment usually with antimalarial were 58$42 \%$ respectively ${ }^{[4,5]}$ According to study done in Oromia Ethiopia show that among those participants who were seeking treatment to health facilities seem to delays averaging three or more days. ${ }^{[4]}$

Knowledge on Early diagnosis and effective treatment seeking of malaria is an essential component to reduce the burden of malaria. ${ }^{[6]}$ This requires appropriate infrastructure and resource, and also active engagement and participation of communities. ${ }^{[7,8]}$ The response to most episodes begins with selftreatment, and close to half of case rely exclusively on self-treatment, usually with antimalarials and the study show the exclusive reliance on traditional methods is extremely rare, although traditional remedies are often combined with modern medicines. ${ }^{[9,10]}$

According to study done in Zambia 2010, show that the early diagnosis of the disease and treatment may be affected by several parameters including percentage of pregnant women receiving prenatal care, education level, government health expenditure, and GDP growth. ${ }^{[11]}$ Treatment-seeking rates, which varied both within and among regions, revealed that public facilities were not always the primary facility type used. ${ }^{[11]}$ Shows that $80.8 \%$ of the respondents reported that going to the hospital was their immediate care-seeking behavior once they felt malaria symptoms, while $11.2 \%$ opted for selfmedication. ${ }^{[4]}$ 
The availability of ACT in all health facilities (government and private health facilities) and diagnostic material (microscopes or MRDT) is important for early diagnosis and proper treatment for the sick person to avoid malaria resurgence and effective surveillance system for breaking transmission. ${ }^{[2]}$ Also it is important to define the nature of self-treatment, record of multiple treatments and attempt to identify the proportions of all cases who begin treatment with antimalarial as standardized time intervals. ${ }^{[4]}$

Early diagnosis and early treatment malaria play roles in reducing disease cases and to prevent death, according to WHO treatment guideline the best treatment recommended is artemisinin-based combination therapy (ACT), diagnostic test need to be taken before administering drugs so as to avoid drug resistance and availability of diagnostic tools in all health facilities is very important. ${ }^{[13,14]}$

Study done in Ethiopia showed that there was lack of knowledge toward treatment seeking behavior and early diagnosis showed that majority had poor knowledge which lead to low level of health-seeking behavior. ${ }^{[15,16]}$ In spite of having Malaria control programs in Tanzania, still there is an increasing number of malaria cases, this situation may be influenced by the people who do not attend to the health facility for diagnosis, adherence of treatment regime and some fail to find medical care when they feel sick, inadequate of diagnostic tools and proper treatment or community does not accept ACT. ${ }^{[15]}$

There is no current study done regarding the knowledge on early diagnosis of malaria and treatment seeking behavior in Mwanza region, henceforth, this study therefore aims to determine the knowledge on early Malaria diagnosis and treatment seeking behavior among clients attending Outpatient department at Sekou-toure Regional referral hospital in Mwanza, Tanzania.

\section{Methods}

\section{Study setting}

This study was conducted in patients who attend outpatient department at Sekou Toure Regional Referral Hospital, which is among the hospital located in Mwanza Region. Mwanza region is among of the six lake zone regions in Tanzania. Sekou Toure Regional Referral hospital serving a population of about

2,773 million. ${ }^{[17,18]}$ The hospital has 315 beds capacity and this hospital has RCH clinic. These hospitals have various clinical specialties such as General internal medicine, General surgery, Gynecology and Obstetrics, Pediatrics and Child health, Orthopedics, Laparoscopic Surgery, Cardiology and Infectious Disease.

\section{Study design}

The cross-sectional hospital-based study was conducted in outpatient client aged 18 years and above attending at Sekou Toure Regional Referral hospital.

\section{Study population}


The study was including all outpatient clients aged 18 years and above attending at Sekou Toure Regional Referral hospital.

\section{Selection criteria}

All outpatient clients aged 18 and above attending at Sekou-Toure Regional Referral hospital during study time and who was willing to participate on the study after consent were included in the study and exclusion involved all outpatient clients aged 18 years and above attending at Sekou Toure regional referral hospital who was refuse to participate and all outpatient clients who was aged below 18 years during study time.

\section{Study sample size and sampling procedure}

The minimum sample size of study participant was obtained by using Kish-Leslie formula (1965). [19] Whereby sample size total of 192 participants were recruited in the study. Simple random sampling was used where by every outpatient client attending at Sekou Toure regional referral hospital have an equal chance to be selected.

\section{Data collection and tools}

Data were collected through structured self-administered questionnaire prepared in English and Swahili language, which was involving all outpatient clients attending at Sekou-toure hospital who were willing and give consent to participate during study.

\section{Data analysis procedure and Statistical analysis}

The data analysis planned to include descriptive and inferential statistics; data was entered into Microsoft excel and then exported to Statistical Package for Social Sciences software (SPSS version 25.0) for further analysis and presented on the percentages and table. The analysis of strength of relationships between categorical variables was conducted using the Chi-square test. A p-value of $<0.05$ was considered to be statistically significant.

\section{Results}

\section{Socio-demographic characteristics}

A total of 192 respondents were interviewed and included in the analysis, after removing forms with major errors and those which were grossly incomplete making the response rate $97.6 \%$. Most of the respondents were male (63.2\%), about (60.4\%) married and about $149(77.6 \%)$ were residing in urban area. The median age was 28 years (IQR 20:35) and 63.5\% were in the age group 24-35 years. Also, 159 (82.8\%) were Christian. In terms of educational background, about (12.5\%) respondent were not able to read and write (no formal education) and about $52.1 \%$ majority of respondents were having primary education level. Also, about (46.9\%) of respondents were unemployed (Table 1 ) 
Table 1

Sociodemographic characteristics

\begin{tabular}{|c|c|c|}
\hline Category & Frequency & Percent \% \\
\hline \multicolumn{3}{|l|}{ Gender } \\
\hline Male & 121 & 63 \\
\hline Female & 71 & 37 \\
\hline \multicolumn{3}{|l|}{ Age(years) } \\
\hline $18-24$ & 19 & 10 \\
\hline $25-34$ & 122 & 63.5 \\
\hline $35-44$ & 30 & 15.4 \\
\hline 45 and above & 21 & 11 \\
\hline \multicolumn{3}{|l|}{ Religion } \\
\hline Christian & 159 & 82.8 \\
\hline Islamic & 28 & 14.6 \\
\hline Pagan & 5 & 2.6 \\
\hline \multicolumn{3}{|l|}{ Marital status } \\
\hline Single & 58 & 31.4 \\
\hline Married & 116 & 60.4 \\
\hline Divorced & 2 & 1 \\
\hline Widow & 12 & 6 \\
\hline Separated & 4 & 2 \\
\hline \multicolumn{3}{|l|}{ Education level } \\
\hline University/ College & 26 & 13.5 \\
\hline Secondary & 42 & 21.9 \\
\hline Primary & 100 & 52.1 \\
\hline Informal & 24 & 12.5 \\
\hline \multicolumn{3}{|l|}{ Family size } \\
\hline Below 5 people & 110 & 57.3 \\
\hline 5 people and above & 82 & 42.7 \\
\hline
\end{tabular}




\begin{tabular}{|lll|}
\hline Category & Frequency & Percent \% \\
\hline Urban & 149 & 77.6 \\
\hline Rural & 43 & 22.4 \\
\hline Occupation & & \\
\hline Private services & 16 & 8.3 \\
\hline Agriculture & 55 & 28.6 \\
\hline Government worker & 20 & 10.4 \\
\hline Business & 11 & 5.8 \\
\hline Unemployed & 90 & 46.9 \\
\hline
\end{tabular}

- Knowledge of early symptoms of malaria and measure taken after the onset of illness among study population

The study respondents about (64.6\%) they had awareness on symptoms of malaria and (35.4\%) they were not aware on symptoms of malaria. Respondents reported that significant malaria symptoms included fever (90\%), headaches (72.6\%), chills /rigor (41.1\%), vomiting (50\%), Joint pain (48.4\%), lack of appetite (56.5\%) and general body weakness (56.5\%). However, significant differences were noted for fever and headaches $p<0.05$. The majority $(87 \%)$ of respondents said that antimalarial drugs were the appropriate medicine for treat malaria and it should be given immediately. (Table 2)

Table 2

Symptoms of malaria as perceived by study population

\begin{tabular}{|c|c|c|}
\hline Symptoms ${ }^{a}$ & $\begin{array}{l}\text { Frequency } \\
(n=192)\end{array}$ & Percent (\%) \\
\hline Fever & 104 & 90 \\
\hline Headache & 90 & 72.6 \\
\hline nausea/vomiting & 62 & 50 \\
\hline Chill/ rigour & 51 & 41.1 \\
\hline Joint pain & 60 & 48.4 \\
\hline loss of appetite & 70 & 56.5 \\
\hline body weakness & 70 & 56.5 \\
\hline I don't know & 69 & 35.9 \\
\hline
\end{tabular}




\section{Measures taken after the onset of malaria illness}

Response to those who were having symptoms during study period up to last 6 months, about 97 (50.5\%) respondents, only (30\%) were seeking for treatment at health facility and majority $70 \%$ self-medicate after buying drugs at pharmacy $(p<0.05)$. Basing on the knowledge about diseases which have the same symptoms as of malaria, only $55(28.6 \%)$ respondents were aware of those conditions compared to $137(71.4 \%)$ of respondents who were not aware of those diseases. Among those who were aware of some disease which have same symptoms as of malaria, (80\%) mentioned urinary tract infection (UTI), Dengue and Typhoid and others $64 \%$ they term fever as the disease. (Table 3 )

Table 3

Action taken after the onset of illness and knowledge of disease which have same symptoms as of Malaria

\begin{tabular}{l|lll|}
\hline Measures Taken after onset of illness & Frequency & Percent \% \\
\hline Going to health facility & 57 & 30 \\
\hline Self-medication & 135 & 70 \\
\hline If yes, which diseases have same symptoms as of malaria? & 34 & 61.8 \\
Urinary tract infection (UTI) & 28 & 51.0 \\
\hline Typhoid & 40 & 64.0 \\
\hline Fever & 40 \\
\hline
\end{tabular}

In the bivariate analysis, among the socio-demographic characteristics of respondents, age, residence, ethnicity, occupation and religion were significantly associated with malaria treatment-seeking behavior. Of the malaria perception variables, perceived susceptibility for malaria, perceived barriers to treatmentseeking and cues to action $(p<0.05)$ were found to affect the treatment-seeking behavior of the people.

Among 192 respondents who seek treatment after onset of illness, about 12(6.3\%) had seek for treatment within 24 hours of onset of illness ( $p=0.017), 84(43.7 \%)$ were seeking for treatment 2-3 days after onset of illness, $96(50 \%)$ decided to seek for treatment when the condition become severe. As shown in (Table 4), seeking treatment within 24 hours of illness onset was not common among people with high literacy rate compared to those with no formal education. 
Table 4

Treatment seeking duration after onset of illness

\begin{tabular}{l|llll|}
\hline Variable & Frequency & Percent \% & p-value \\
\hline Within 24 hours after feeling the symptoms & 12 & 6.3 & $<0.04$ \\
\hline After 2-3 days of symptoms & 84 & 43.7 & $<0.05$ \\
\hline After condition become severe & 96 & 50.0 & 0.0734 \\
\hline
\end{tabular}

Toward measures taken after the onset of illness (Table 5), about (98.4\%) they respond positive that they tend to seek for treatment and regarding where they tend to seek for treatment, about $114(59.4 \%)$ tend to go to health facility, $10(5.2 \%)$ tend to seek spiritual leaders, $1(0.52 \%)$ tend to seek traditional healer for treatment, 31(16.1\%) were using traditional medicine and homemade remedy, and $20(10.4 \%)$ they tend to go to spiritual leaders, using homemade remedy and going to health facility if condition become chronic. (figure 1)

Table 5

Treatment seeking behavior and treatment facility of choices among study population after onset of illness

\begin{tabular}{|llll|}
\hline Variable & Frequency & Percent \% & p-value \\
\hline Prompt seeking treatment after onset of illness & & & \\
\hline Health facility & 114 & 59.4 & $<0.05$ \\
\hline Seek spiritual leaders & 10 & 5.2 & 0.546 \\
\hline Seek traditional healer & 1 & .52 & 0.780 \\
\hline Using traditional medicine and home-made remedy & 31 & 16.1 & 0.233 \\
\hline All of the above & 20 & 10.4 & 0.093 \\
\hline
\end{tabular}

\section{Treatment seeking rate at health facilities after the onset of malaria illness}

The findings of this study show the first health facility of choice when they seek for treatments. whereby, about $98(51 \%)$ respondents were preferring to seek treatment at nearby pharmacy (drug shops) to buy medicine for self-treatment. Number of people who seek for treatment at pharmacy and local drug shops were higher compared to those who seeking for treatments in other health facilities. Overall, about $41(21.4 \%)$ respondents were preferring to go first at labratory nearly home and only $51(26.6 \%)$ respondents were seeking treatment to nearly health center. Overall, cost of service, time consumed and distance of health facility especially health center shows correlation with delayal in treatment seeking $(p<0.05)$. (see figure 2) 


\section{Treatment regime for malaria illness}

Study showed different type of medicine they use for treatment after being discovered to have malaria parasite, study finding show statistically significant as majority about $166(86.5 \%)$ were using Artemisinin based combination (ACT/ ALU) which is the recommended regime for malaria treatment by WHO, whereby among those who utilizing ACT only (65.6\%) respondents believe that this combination is effective in malaria treatment and other's believed that ACT's were not effective for treatment of malaria, whereby some commend that the drug it not effective as disease tend to relapse and others says the drugs tend to increase the magnitude of disease that's why they were using with other herbal medicine for effective treatment and about $3(1.6 \%)$ they don't know the type of medicine they were using for treatment. (Figure 3)

On extent of utilizing the prescribed antimalarial drug for treatment, about $98(51 \%)$ respondents were adhering on antimalarial drugs till they finish dose, $82(42.7 \%)$ respondents were stop using medication after feeling a relief of being healed and $12(6.3 \%)$ respondents were stop using antimalaria when they feel tired of taking medication. (Figure 4)

\section{Factors affecting early treatment seeking behavior within study population}

Findings of this study show revealed that, people they tend to delay to seek treatment early after the onset of illness due to several circumstances whereby about $51 \%$ of respondents long distance from their area of residence to health facility act as a hindrance for them to seek treatment earlier, also the cost of health care services, time consumed in health facility especial at hospital and other self-treated without going to hospital. (See Figure 5)

\section{Discussion}

This cross-sectional study was conducted to determine the community behavior towards early diagnosis and early treatment seeking after the onset of malaria disease. The finding of this study revealed that education level, level of income, knowledge toward malaria, environmental factors such as accessibility, affordability and availability of services, maleness and desirable facility for treatment were the common factors that contributing in delayal to seek treatment after the onset of illness. Whereby, level of knowledge toward malaria illness was high about $65 \%$ but the response toward prompt treatment seeking was very low, whereby about $93.7 \%$ delay to seek treatment within 24 hours after onset of illness and they took 2-3 days and some go to health facility when condition become severe. This seem similar to study done in Kenya ${ }^{[20]}$ and Myanmar ${ }^{[21]}$

Moreover, finding of this study shows that educational level and knowledge on symptoms of malaria $(P<0.05)$ were found having significant association with early treatment seeking behavior. Although the knowledge was adequate, $65 \%$ have knowledge but the practices of early treatment seeking behavior of 
malaria was low. This also could be due to community's inability to distinguish malaria's symptoms with other similar diseases and other febrile illness in the first two days of onset of the illness. Similar findings were reported in Ethiopia, Eritrea and Myanmar. ${ }^{[22,23,24]}$

The health facility where people prefer to seek for treatments after the onset of illness, study show that majority of people they tend to seek treatment earlier at pharmacy (drug shop) to buy medicine for selftreatment than other places like hospital or health center and laboratory. ${ }^{[24]}$ The number of people who seek for treatment at pharmacy and local drug shops were higher compared to those who seeking for treatments in other health facilities. These reveal the peoples knowledge on importance of going at health center or hospital for early diagnosis and treatment is very low, the cost of services at hospital including hospital registration fee and other chargers is higher where majority of people they prefer to go to pharmacy where the cost of service and drug is affordable and not time consuming, Also distance to nearby hospital/health center seem as hindrance in early treatment-seeking and hence lead to delayal. Compared to study done in Ethiopia ${ }^{[25]}$

Gender effect on treatment seeking behavior, study shows that most of male sought to delay in treatment seeking than female. This rate is higher compared to other study done in Canada, which showed both male and female were equally seeking for healthcare early. ${ }^{26]}$

Our study findings show that, those who residing in rural areas were found to seek health care more than those who residing in urban. This study finding may be explained by the fact that those who residing in urban are relatively more educated, with better access to pharmacies and drug shops and thus the tendency to self-treat, as about Studies have reported that perceived efficacy is related with tendency for self-treatment of malaria and there is no study relating to these findings.

Self-treatment was common, most of respondents did not seek appropriate care within 24 hours after onset of clinical symptoms. Delays of more than 24 hours in care seeking has also been reported in other studies. ${ }^{[27]}$ The study reports that among those with undifferentiated fever, less than one-third get their blood tests done for malaria despite the fact that most of them seek care ${ }^{[28]}$

Findings of this study reveal high cost of services and long distances to health facilities were the challenges affecting treatment seeking behavior as many they sought to delay at health facility for somedays, whereby $73 \%$ they did not prefer to go at health facility till the condition seem to persisted. Compared to studies done Eritrea showed that cost is often a barrier to seeking health services especially among the poor ${ }^{[22]}$

\section{Limitation of the study}

Inadequate fund to carry out this study, Language barrier as most of people they speak in Sukuma language, the study requires a larger number of participants hence was consumed time in data collection and analysis. 


\section{Conclusion And Recommendations}

Therefore, findings of this study indicate that a health education strategy stressing the importance of prompt seeking-treatment within 24 hours of onset of symptoms. A low proportion of malaria-suspected patients sought treatment within $24 \mathrm{~h}$ of fever onset compared to the national target. Distance from the health centres, cost of service and time consumed were found to be predictors of early treatment-seeking behavior for malaria. Strengthening strategies tailored to increasing awareness for communities about malaria, importance of going hospital and early treatment-seeking behavior is essential.

In order to tackle leading challenges toward prompt treatment seeking behavior, there are needs to be provided including improved orientation toward malaria illness through mass media and other sources, education to health care provider to both medical and paramedical personnel with regard to changes in treatment policy. Also, the need to inform and educate patients and drug vendors on changes in treatment policy should not be neglected.

\section{Declarations}

\section{Acknowledgments}

The authors acknowledge the support of Sr. Gotfrida Marandu for her acceptance and tireless support and guidance throughout the process of developing the research. With all her efforts, she deserves appreciation for her encouragement, moral and technical support. Medical officer incharge of Sekoutoure regional referral hospital in Mwanza for granting permission to conduct this study and all respondents. We also grateful to technical support from Shugha J.

\section{Disclosure statement}

No potential conflict of interest was reported by the authors

\section{Ethics and Consent}

Ethical clearance for conduction of this study was obtained from joint CUHAS-BMC research and ethics review committee No. 1824/2021 and permission from Medical officer in charge of Sekou-Toure regional referral Hospital FA.137/264/01J/14. Written informed consent was obtained from participants and confidentiality was guaranteed. No participant name filled in the form to ensure confidentiality and right to withdraw from the study.

\section{Funding}

No funding

\section{References}


1. Tanzania's Ministry of Health, Gender, Elderly and Children. Tanzania Demographic and Health Survey and Malaria Indicator Survey (TDHS-MIS) 2015-2016; Dec. 2016. [Online]. Available: https://dhsprogram.com/publications/publication-fr321-dhs-final-reports.cfm.

2. Ministry of Health and Social Welfare. National Malaria Strategic Plan 2014-2020. Dar Es Salaam: Ministry of Health and Social Welfare.; 2014.

3. D’Acremont V, Bosman A. WHO informal consultation on fever management in peripheral health care settings: a global review of evidence and practice. Geneva: World Health Organization; 2013. p. 75964

4. Regassa H, Taffere GR, Gebregergs GB. Delay in malaria diagnosis and treatment and its determinants among rural communities of the Oromia special zone, Ethiopia: facility-based crosssectional study. J Public Heal. 2018;26(3). doi:10.1007/s10389-017-0863-7

5. Sumari D, Dillip A, Ndume V, Mugasa J, Gwakisa P. Knowledge, Attitudes and Practices on Malaria in Relation to its Transmission: Among Primary School Children in Bagamoyo District, Tanzania. Malaria World J. 2016;7(2).

6. WHO: Global Malaria Control and Elimination: report of a technical review, World Health Organization Global Malaria Programme. Geneva: WHO; 2018.

7. Yadav SP. A study of treatment seeking behavior for malaria and its management in febrile children in rural part of desert, Rajasthan, India. J Vector Borne Dis. 2010;47(4):235-242.

8. S.P. Yadav, S. Yadav, P. Kuma. Knowledge, treatment-seeking behavior and socio-economic impact of malaria in the desert of Rajasthan, India, Southern African Journal of Epidemiology and Infection, 2013;28:1, 41-47.

9. Battle KE, Bisanzio D, Gibson HS, et al. Treatment - seeking rates in malaria endemic countries. Malar J. 2016:1-11. doi:10.1186/s12936-015-1048-x

10. Okonofua FE, Feyisetan BJ, Davies-Adetugbo A, Sanusi YO. Influence of socioeconomic factors on the treatment and prevention of malaria in pregnant and non-pregnant adolescent girls in Nigeria. $J$ Trop Med Hyg. 1992;95(5):309-315.

11. McCombie SC. Treatment seeking for malaria: A review of recent research. Soc Sci Med. 1996;43(6):933-945. doi:10.1016/0277-9536(95)00446-7

12. Tanzania HIV \& Malaria Indicator Survey THMIS 2011-12.

13. World Health Organization, World Malaria Report, 30 November 2020

14. World Health Organization. Guideline for the treatment of Malaria $-3^{\text {rd }}$ edition 2015. http//; www.who.int/malaria/docs/Treatment Guidelines2015.pdf

15. Mitiku, I., Assefa, A. Caregivers' perception of malaria and treatment-seeking behavior for under five children in Mandura District, West Ethiopia: a cross-sectional study. Malar J 16, 144 (2017).

16. Asfaw LS, Ayanto SY, Aweke YH. Health-seeking behavior and associated factors among community in Southern Ethiopia: Community based cross-sectional study guided by Health belief model. BioRxiv. 2018 Jan 1:388769. 
17. Ministry of Health and Social Welfare. National Malaria Strategic Plan 2014-2020. Dar es Salaam: Ministry of Health and Social Welfare; 2014.

18. Msekela, James Alex (29 December 2007). "Brief Remarks by Hon. Eng. Dr. James Alex Msekela (MP) Regional Commissioner for Mwanza Region to Mr. Ahmed al Marar - 11H - Chairman and Managing Director of the Abu Dhabi Islamic Bank on 29th December 2007"

19. Kish L. Survey sampling: John Willey and Sons. Inc. NY. 1965.

20. Sumba PO, Wong SL, Kanzaria HK, Johnson KA, John CC. Malaria treatment-seeking behaviour and recovery from malaria in a highland area of Kenya. Malar J. 2008;7(May 2014).

21. Naing PA, Maung TM, Tripathy JP, Oo T, Wai KT, Thi A. Awareness of malaria and treatment-seeking behaviour among persons with acute undifferentiated fever in the endemic regions of Myanmar. Trop Med Health. 2017;45(1).

22. Andegiorgish AK, Kidane EA, Welday BE, Weldeghiergis M. Knowledge , Attitude and Treatment Seeking Behavior for Malaria in May-Aynee Administration, Eritrea. 2019;(December).

23. Dida N, Darega B. Treatment Seeking Behavior and Associated Factors Among Malaria Suspected Patients in Bale Zone, Southeast Ethiopia: Institution-Based Cross-sectional Study. J Fam Med. 2015;2(2).

24. Xu JW, Xu QZ, Liu H, Zeng YR. Malaria treatment-seeking behaviour and related factors of Wa ethnic minority in Myanmar: A cross-sectional study. Malar J. 2012;11.

25. Workineh, B., Mekonnen, F.A. Early treatment-seeking behavior for malaria in febrile patients in northwest Ethiopia. Malaria Journal. 17, 406 (2018). https://doi.org/10.1186/s12936- 018-2556-2

26. Thompson AE, Anisimowicz Y, Miedema B, Hogg W, Wodchis WP, Aubrey-Bassler K. The influence of gender and other patient characteristics on health care-seeking behaviour: A QUALICOPC study. BMC Fam Pract [Internet]. 2016;17(1):1-7. Available from: http://dx.doi.org/10.1186/s12875-016-0440-0

27. Mitiku I, Assefa A. Caregivers' perception of malaria and treatment-seeking behaviour for under five children in Mandura District, West Ethiopia: A cross-sectional study. Malaria Journal. 2017; Dec;16(1):1-0

28. Naing PA, Maung TM, Tripathy JP, Oo T, Wai KT, Thi A. Awareness of malaria and treatment-seeking behaviour among persons with acute undifferentiated fever in the endemic regions of Myanmar. Trop Med Health. 2017 Dec;45(1):1-0. https://doi.org/10.1186/s41182-017-0070-9

\section{Figures}




\section{Treatment choices}

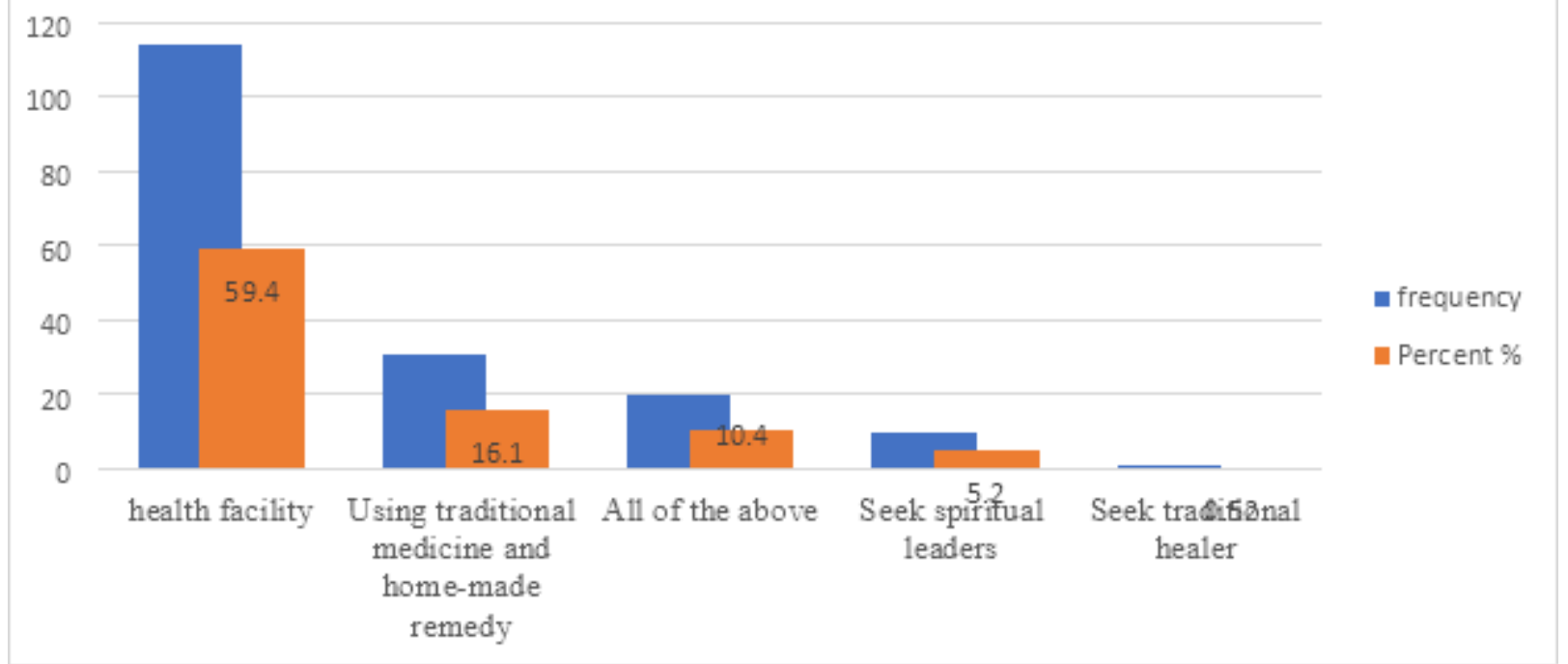

Figure 1

Bar chart showing the facility of choices of where they seek for treatment after the onset of illness

\section{Treatment seeking rate at Health facilities}

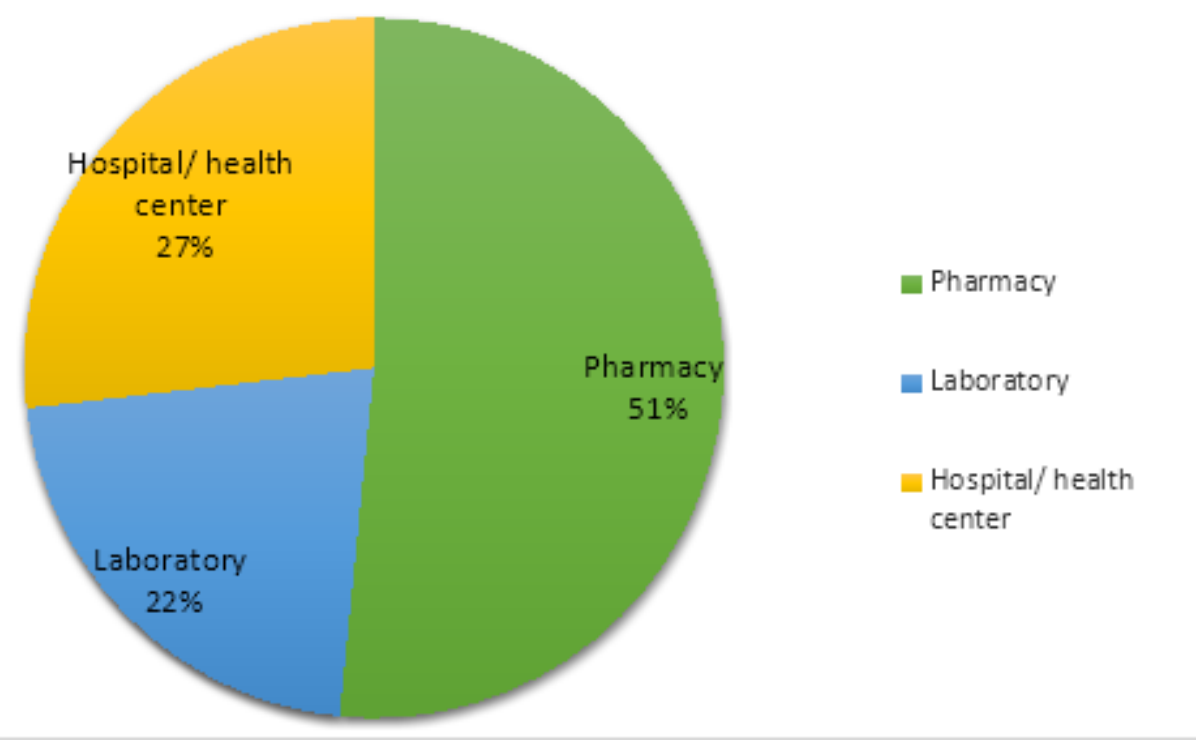

Figure 2

Population treatment seeking rate at health facilities after the onset of malaria illness 


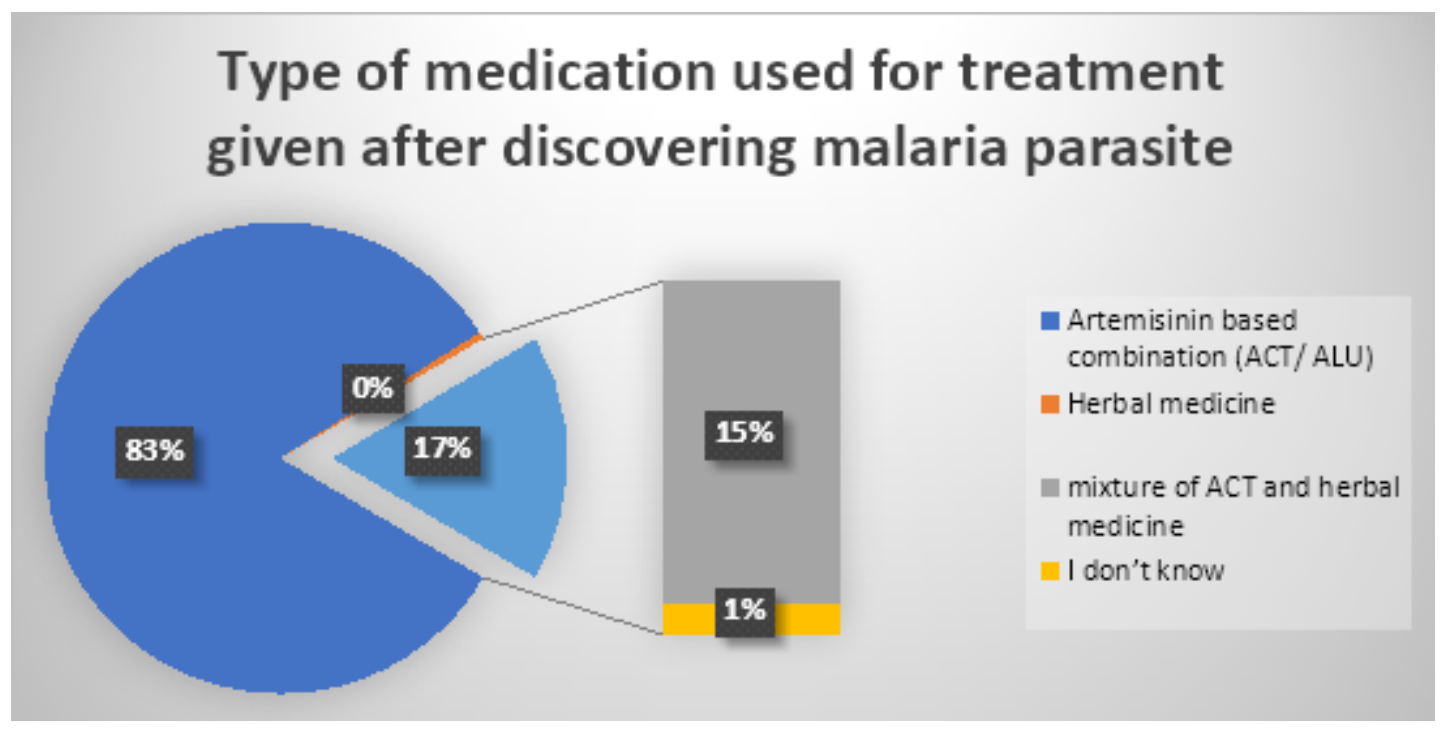

Figure 3

Type of medication used for treatment given after discovering malaria parasite

\section{Adherence of Malaria treatment}

After feel tired to take medication

Finish prescribed drug dose

After feeling relief of being fine

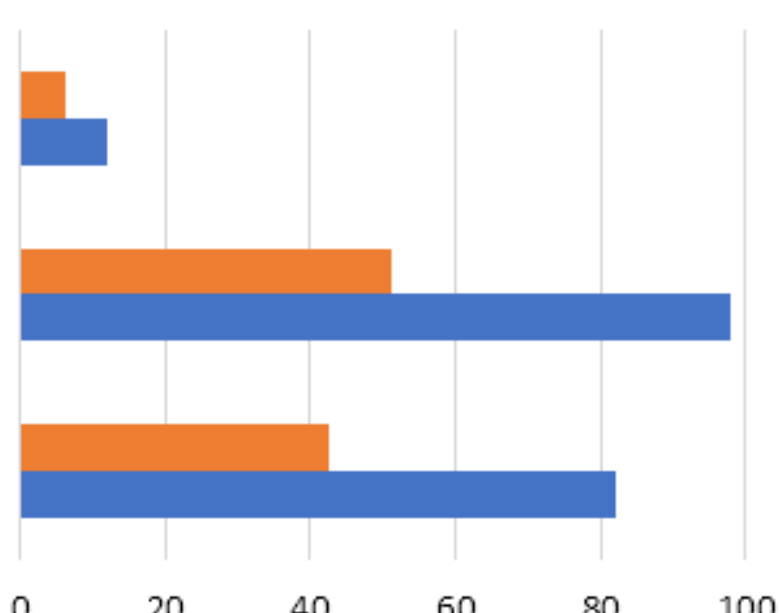

$\begin{array}{lrrrrr}0 & 20 & 40 & 60 & 80 & 100 \\ & \text { m percent } & \text { q frequency }\end{array}$

\section{Figure 4}

Adherence of antimalaria drug for treatment 


\section{Factors contributing in delayal to seek treatment}
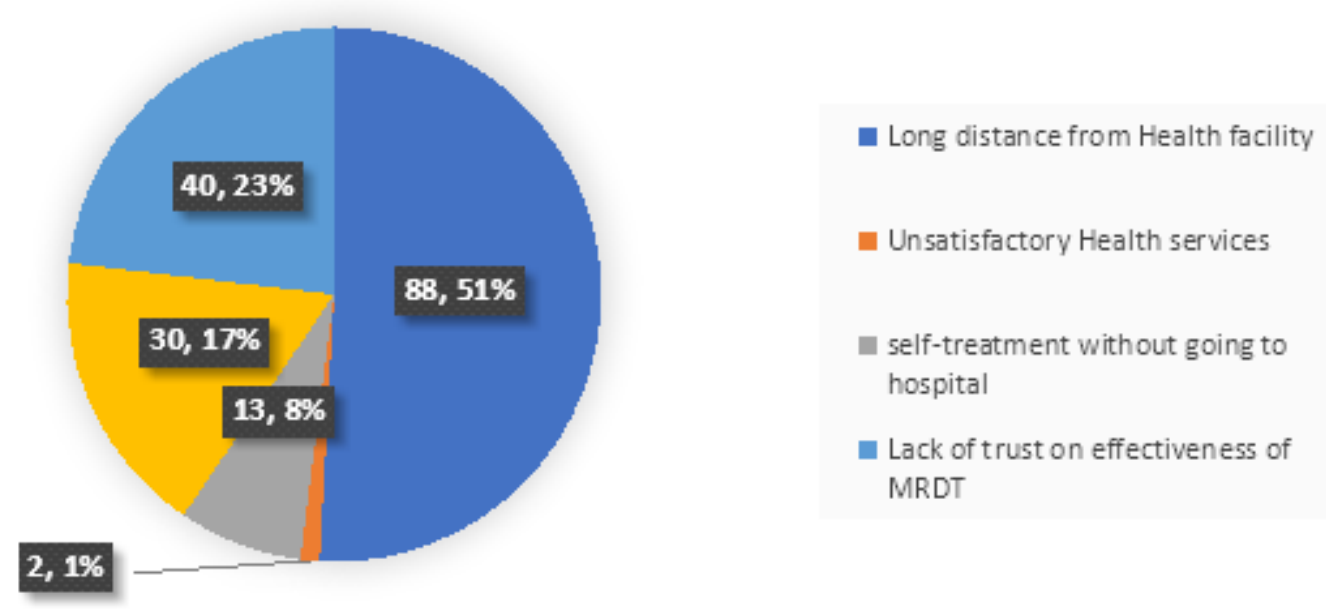

Figure 5

Causes of delay for early treatment-seeking after onset of illness 